\title{
Epithelial ovarian cancer and exposure to dietary nitrate and nitrite in the NIH-AARP Diet and Health Study
}

\author{
Briseis Aschebrook-Kilfoya, Mary H. Ward ${ }^{\mathrm{a}}$, Gretchen L. Gierach ${ }^{\mathrm{b}}$, Arthur Schatzkin ${ }^{\mathrm{c}, *}$, \\ Albert R. Hollenbeck ${ }^{d}$, Rashmi Sinha ${ }^{c}$, and Amanda J. Cross ${ }^{c}$ \\ aOccupational and Environmental Epidemiology Branch, DCEG, NCI, NIH bHormonal and \\ Reproductive Epidemiology Branch, DCEG, NCl, NIH ${ }^{\circ}$ Nutritional Epidemiology Branch, Division \\ of Cancer Epidemiology and Genetics, National Cancer Institute, National Institutes of Health, \\ Rockville, Maryland dAARP, Washington, District of Columbia, USA
}

\begin{abstract}
Ovarian cancer is a leading cause of cancer death among women in the United States and it has the highest mortality rate of all gynecologic cancers. Internationally, there is a five-fold variation in incidence and mortality of ovarian cancer, which suggests a role for environmental factors, including diet. Nitrate and nitrite are found in various food items and they are precursors of $\mathrm{N}$ nitroso compounds, which are known carcinogens in animal models. We evaluated dietary nitrate and nitrite intake and epithelial ovarian cancer in the National Institutes of Health (NIH)-AARP Diet and Health Study, including 151316 women aged 50-71 years at the time of the baseline questionnaire in 1995-1996. The nitrate and nitrite intake was assessed using a 124-item validated food frequency questionnaire. Through 31 December 2006, 709 incident epithelial ovarian cancer cases with complete dietary information were identified. Using Cox proportional hazards regression to estimate hazard ratios and $95 \%$ confidence intervals (CIs), women in the highest intake quintile of dietary nitrate had a $31 \%$ increased risk (95\% CI: 1.01-1.68) of epithelial ovarian cancer, compared with those in the lowest intake quintile. Although there was no association for total dietary nitrite, those in the highest intake category of animal sources of nitrite had a $34 \%$ increased risk (95\% CI: 1.05-1.69) of ovarian cancer. There were no clear differences in risk by histologic subtype of ovarian cancer. Our findings suggest that a role of dietary nitrate and nitrite in ovarian cancer risk should be followed in other large cohort studies.
\end{abstract}

\author{
Keywords \\ epithelial; nitrate and nitrite; ovarian cancer
}

\section{Introduction}

Ovarian cancer has the highest mortality rate of all of the female cancers and more than 13 000 American women are expected to be diagnosed with the disease in 2010 (Jemal et al., 2010). Few modifiable risk factors for ovarian cancer have been identified and the etiology

\footnotetext{
(C) 2011 Wolters Kluwer Health | Lippincott Williams \& Wilkins

Correspondence to Dr Briseis Aschebrook-Kilfoy, Occupational and Environmental Epidemiology Branch, Division of Cancer Epidemiology and Genetics, Department of Health and Human Services, National Cancer Institute, NIH/DHHS, 6120 Executive Boulevard, EPS 8111, Rockville 20852, MD, USA Tel: + 301435 2358; fax: + 301402 1819; kilfoyb@ mail.nih.gov.

* Deceased.

Conflicts of interest

There are no conflicts of interest.
} 
of this malignancy is poorly understood (Byers et al., 1983; Mori et al., 1988; Hankinson and Danforth, 2006; Moorman et al., 2009). However, the five-fold international variation in ovarian cancer incidence and mortality (Baker and Piver, 1994) and the increase in incidence in migrants from Japan to the United States (Dunn, 1975; Herrinton et al., 1994) strongly suggest a role for environmental factors, including diet. There is limited data on the relation between diet and ovarian cancer (Hankinson and Danforth, 2006). Investigation of the role of nitrate and nitrite in ovarian cancer risk is of interest as these compounds are precursors for the endogenous formation of $N$-nitroso compounds (NOC), which have been shown to induce tumors in animals (Bogovski and Bogovski, 1981) and potentially in humans (McKnight et al., 1999).

Nitrate is a natural component of plants and is found at high concentrations in leafy vegetables, such as lettuce and spinach, and some root vegetables, such as beets (Gangolli et al., 1994). Nitrate is also present as a contaminant in drinking water, which can be a major source of intake when levels are at/above the maximum contaminant level (MCL) of $10 \mathrm{mg} / \mathrm{l}$ nitrate-nitrogen (Chilvers and Caygill, 1984). Nitrite and nitrate salts are added to cured meats such as bacon, hot dogs, and ham to prevent the growth of spore-forming bacteria as well as to add color and flavor (Lück, 1985).

The relation between nitrate levels in municipal drinking water and ovarian cancer risk was evaluated previously in a cohort of 21977 women in Iowa (USA) (Weyer et al., 2001). The investigators observed increasing relative risks (RRs) of 1.0, 1.52, 1.81, and 1.84 for ovarian cancer ( $n=102$ cases) across increasing quartiles of municipal nitrate water concentrations; however, the relationship between dietary nitrate intake and ovarian cancer was null (Weyer et al., 2001). Using prospective data from the National Institutes of Health (NIH)-AARP Diet and Health Study, we evaluated the relationship between dietary nitrate and nitrite intake and epithelial ovarian cancer incidence. This large cohort allowed us to evaluate associations after accounting for factors previously shown to influence endogenous $N$ nitrosation reactions (Mirvish, 1996), including cigarette smoking and intake of vitamins $\mathrm{C}$ and $\mathrm{E}$.

\section{Participants and methods}

\section{Study population}

The NIH-AARP Diet and Health Study was initiated in 1995-1996 when an extensive baseline questionnaire was mailed to 3.5 million AARP members aged 50-71 years residing in one of six US states (California, Florida, Pennsylvania, New Jersey, North Carolina, and Louisiana) and two US metropolitan areas (Atlanta, Georgia, and Detroit, Michigan; Schatzkin et al., 2001). This questionnaire ascertained information on usual dietary intake over the past 12 months, use of individual and multivitamin supplements, smoking history, alcohol intake, height and weight at baseline, reproductive history, menopausal status, and other factors. A total of 617119 persons returned the baseline questionnaire, and 567169 questionnaires were determined to have been satisfactorily completed. The NIH-AARP Diet and Health Study was approved by the Special Studies Institutional Review Board of the National Cancer Institute.

Among the 226733 women with satisfactory baseline questionnaires, there remained 200 571 women after excluding those with duplicate questionnaires, those who had died or moved out of the study area prior to baseline, those who withdrew from the study, and those who had questionnaires completed by proxy respondents. We further excluded those who had been previously diagnosed with cancer except for nonmelanoma skin cancer ( $n=26546$ ) and those with extreme values for total energy intake (i.e. beyond twice the interquartile range of Box-Cox log-transformed intake, corresponding to <317 and >4791 kcal/day; total: 
$n=1836)$. We additionally excluded women who had a bilateral oophorectomy or unknown oophorectomy status at baseline ( $n=20855$ ), no follow-up time ( $n=10)$, or an extreme body mass index (BMI, $\unlhd 2 \mathrm{~kg} / \mathrm{m}^{2}$ or $\geq 45 \mathrm{~kg} / \mathrm{m}^{2} ; n=8$ ). After these exclusions, 151316 women were available for analysis.

\section{Cancer ascertainment}

Incident, first primary epithelial ovarian cancer cases, topography code C56.9 of the International Classification of Diseases for Oncology, Third Edition (World Health Organization, 2001), were identified through 31 December 2006, by linkage of the cohort database to cancer registries of the eight original plus two additional states (Texas and Arizona), and the National Death Index Plus. By histologic subtype, total incident epithelial ovarian cancer cases included the International Classification of Diseases for Oncology, Third Edition histology codes 8000-8573; serous cancers included 8441, 8450, 8460, 8461, and 8462; endometrioid included 8380, 8381, 8560, and 8570; and mucinous included 8470, $8471,8480,8481$, and 8490 .

\section{Dietary intake}

The dietary component of the baseline questionnaire asked about the frequency of consumption and corresponding portion sizes of 124 food items, including 14 fruits and 23 vegetables, and fresh and processed meats, during the past 12 months. Participants were queried about their frequency of intake in 10 categories ranging from 'never' to ' $2+$ times per day' for foods and 'never' to ' $6+$ times per day' for beverages. Each line item was accompanied by three possible portion size categories. The food items, portion sizes, nutrient database, and Pyramid Food Servings database were utilized using methods developed by Subar et al. (2000) with national dietary data from the US Department of Agriculture's 1994-1996 Continuing Survey of Food Intakes by Individuals (CSFII; Friday, 2006). The Pyramid Food Servings database used a recipe file to disaggregate food mixtures into their component ingredients and assign them to food groups.

The food frequency questionnaire (FFQ) was validated using two $24 \mathrm{~h}$ recalls in a subset of the cohort (Thompson et al., 2008). In the validation study, the investigators found that for the 26 nutrient constituents examined, when adjusted for reported energy intake, the estimated correlations with true intake ranged from 0.36 to 0.76 and the attenuation factors ranged from 0.24 to 0.68 . These results compare favorably with those from other large prospective studies. For fruits and vegetables, the adjusted correlation was 0.71 in men and 0.61 in women. For vitamin C, the adjusted correlation was 0.70 for men and 0.65 for women. However, for protein, the adjusted correlation was lower, with 0.43 for men and 0.50 for women.

The nitrite and nitrate content in over 3000 foods were determined by conducting a review of the literature, focusing on US and Canadian foods, and calculating means of the published values weighted by the number of food samples analyzed (Ward et al., 2006). If values from US or Canadian foods were unavailable, we used values from other western countries. The nitrite and nitrate values for foods constituting a FFQ line item were combined by weighting the food-specific values by sex-specific intake amounts from the 1994-1996 CSFII (Subar et al., 2000). For example, the nitrate content of a line item was calculated using a weighted average of the nitrate content in the included foods where the weights were determined by intake amounts from the CSFII, specific for the age group and sex. Daily intakes of nitrate and nitrite were calculated by multiplying the frequency of consumption of each line item by its nitrate or nitrite content and summing over line items. In addition to calculating dietary nitrite and nitrate from all foods, we calculated nitrite from plant, animal, and processed meat sources separately. 
Although information about the usual source of drinking water and tap water intake was not assessed for the cohort, we used the census tract location of a participant's residence at enrollment to estimate the likelihood that they may have been exposed to elevated nitrate concentrations by their drinking water supply in a Geographic Information System. First, residential addresses for all participants were geocoded to a census tract. Using ESRI's ArcInfo (Redlands, California, USA) Geographic Information System software we linked the census tract to a geospatial model developed by Nolan and Hitt (2006) that predicts nitrate contamination of ground water used for drinking water across the continental US. The predicted nitrate concentration represents average levels in an area of approximately 20 square kilometers, which is the minimum size of the US Geological Survey ground water monitoring network. Ground water provides drinking water for more than one-half of the US population (Solley et al., 1993), and is the sole source of drinking water for many rural communities and some large cities. The model includes variables that are significant predictors of nitrate in ground water including nitrogen fertilizer and manure applications, the location of orchards/vineyards, aquifer rock type, and population density, and provides a predicted nitrate concentration level $(0-5,>5-10,>10 \mathrm{mg} / \mathrm{l}$ nitrate- $\mathrm{N})$.

We overlaid the $1 \mathrm{~km}$ by $1 \mathrm{~km}$ grid of predicted nitrate levels across the United States onto study participants' census tracts. Using the Tabulate Area Tool in the Spatial Analyst extension of ESRI's ArchInfor (Redlands), we calculated the area within each census tract that intersected areas estimated to have an average nitrate level of $10 \mathrm{mg} / \mathrm{l}$ or more, the MCL. We identified participants who resided in census tracts where $50 \%$ or more of the area was estimated to overlie groundwater with nitrate levels of $10 \mathrm{mg} / \mathrm{l}$ or greater; because their nitrate intake from water sources might have exceeded that from their diet, we excluded these participants in sensitivity analyses.

\section{Statistical analysis}

Person-years of follow-up for each participant accrued from the date of return of the baseline questionnaire to the date of ovarian cancer diagnosis, the date of moving out of the registry ascertainment area, death, or the end of the follow-up period. Cox proportional hazards regression models with person-years as the underlying time metric were used to estimate hazard ratios (HR) and 95\% confidence intervals (CIs) for ovarian cancer within quintiles of dietary intake. Tests for linear trend were conducted using the median value of each exposure category as an ordinal variable in the model. Dietary variables were adjusted for energy intake using the nutrient density method (Willett, 1998), which expresses intake in units per 1000 calories. The proportional hazards assumption was tested and upheld in all analyses.

In all models, we adjusted for age (continuous), cigarette smoking status (never, current, former), race (White, Black, other, missing), family history of cancer (yes, no), BMI ( $<25$, $25-29.9,30-34.9, \geq 35 \mathrm{~kg} / \mathrm{m}^{2}$ ), menopausal status at baseline (premenopausal, natural $<45$ years, natural 45-49 years, natural 50-54 years, natural $\geq 55$ years, surgical, unknown), parity (nulliparous, 1, 2, or 3 or more children), age at menarche ( $₫ 2$ years, 13-14 years, $\geq 15$ years). The family history of cancer variable did not specify ovarian cancer. We adjusted for total daily dietary vitamin $\mathrm{C}$ intake $(\mathrm{mg} / 1000 \mathrm{kcal})$ in the risk model by quintiles of nitrate and nitrite but not in the joint effect model (combined effects of nitrate and nitrite and vitamin $\mathrm{C}$ ).

To test for effect modification (statistical interaction) by total dietary vitamin $\mathrm{C}$ and vitamin E intake, we included these continuous variables in a multivariate model with a cross product term. We assessed multiplicative interactions by adding the relevant cross-product term to main-effects models, with the $P$ value for interaction determined by a Wald test for the cross-product term. 
To evaluate the consistency of associations, we stratified by age (above/below the median age of 62.6 years), BMI (above/below median of $27 \mathrm{~kg} / \mathrm{m}^{2}$ ), and education (high school or fewer years of education; some college or more years of education). We stratified by smoking status (ever/never), red meat intake (above/below median of $26.1 \mathrm{~g} / 1000 \mathrm{kcal}$ ), and vitamin C intake (above/below median of $90.8 \mathrm{mg} / 1000 \mathrm{kcal}$ ) to evaluate factors potentially affecting endogenous $N$-nitrosation. We repeated our analyses in a subsample restricted to those women identified by geocoding as potentially having low intake levels of nitrate from drinking water. For all comparisons, $P$ values were two-sided and $a<0.05$ was considered statistically significant.

\section{Results}

A total of 709 incident epithelial ovarian cancer cases were identified during an average of 10 years of follow-up. Of these, 374 were serous, 66 were endometrioid, and 35 were mucinous tumors. The remaining 234 epithelial ovarian cancer cases included clear and transitional cell tumors, and tumors with other rare and unknown histologies.

Women in the highest quintiles of nitrate and nitrite intake were less likely to be current smokers, had a lower BMI, and had lower intakes of total calories and processed meat as compared with women in the lowest quintiles of nitrate and nitrite intake (Table 1). Furthermore, women in the highest quintiles of nitrate and nitrite intake were more likely to be highly educated, more physically active, and consumed more fruits and vegetables than those in the lowest quintiles. Women who consumed more nitrate consumed less processed meat, whereas women who consumed higher levels of nitrite consumed higher levels of processed meat. Although women in the highest quintile of nitrite intake were less likely to be a current smoker and consumed fewer calories, they tended to be more educated, more physically active, and more likely to consume fruits, and vegetables, than those in the lowest quintile. No difference in nitrate or nitrite intake was observed for the reproductive factors evaluated (data not shown).

The mean dietary nitrate intake in the total study population was $91.9 \mathrm{mg} / \mathrm{day}$ [standard deviation $(\mathrm{SD})=68.6 \mathrm{mg} / \mathrm{day}$ ] and the mean dietary nitrite intake was $1.1 \mathrm{mg} /$ day $(\mathrm{SD}=0.5$ $\mathrm{mg}$ /day). The average intake of nitrate from plant sources was $86.7 \mathrm{mg} /$ day or $94.9 \%$ of total nitrate intake, whereas average intake of nitrite from plant sources was $0.73 \mathrm{mg} / \mathrm{day}$ or $66.3 \%$ of the total nitrite intake. The average intake of nitrate from animal sources was 4.7 $\mathrm{mg} /$ day or $5.1 \%$ of the total nitrate intake, whereas average intake of nitrite from animal sources was $0.3 \mathrm{mg} /$ day or $27.3 \%$ of the total nitrite intake. The average of the combined nitrate and nitrite intake from processed meat sources was $0.84 \mathrm{mg} /$ day $(\mathrm{SD}=1.02 \mathrm{mg} / \mathrm{day})$.

The major contributors to nitrate intake were lettuce (30.7\%), cooked spinach $(8.8 \%)$, and broccoli (5.3\%). The major contributors to nitrite intake were pasta $(6.7 \%)$, rice $(6.2 \%)$, and hot cereal (5.6\%). Processed meats contributed $10.0 \%$ to total nitrite intake and $30.5 \%$ to nitrite intake from animal sources. As the major sources of nitrate were vegetables, which also contain beneficial nutrients such as vitamin $\mathrm{C}$, we evaluated the correlation of intake of vitamin $\mathrm{C}$ with nitrate intake in our study population. The correlation coefficient for nitrate and vitamin $\mathrm{C}$ was 0.39 .

In Table 2, we tested the hypotheses that nitrate and nitrite intake are associated with increased risk of epithelial ovarian cancer and investigated these associations by histologic subtypes. Women in the highest, compared with the lowest, quintile of nitrate intake had an elevated risk of ovarian cancer, and the trend across increasing quintiles was borderline statistically significant (Q5 vs. Q1, HR=1.31; 95\% CI: $1.01-1.68, P$ trend= 0.06 ). Although total nitrite intake was not associated with risk, we observed a positive association between 
nitrite from animal sources and epithelial ovarian cancer risk (Q5 vs. Q1, HR=1.34; 95\% CI: 1.05-1.69, $P$ trend=0.02). In contrast, neither nitrite from plants nor processed meat sources were associated with ovarian cancer risk. We also evaluated food sources rich in nitrate and nitrite, including intake of red and processed meats, as well as fruits and vegetables, and no statistically significant differences in epithelial ovarian cancer risk were identified (data not shown).

In general, there were no clear differences in risk according to histologic subtypes; although for those in the highest quintile of total nitrate, the risks were elevated for serous (Q5 vs. Q1, $\mathrm{HR}=1.27$; 95\% CI: 0.90-1.78, $P$ trend=0.08) and endometrioid subtypes (Q5 vs. Q1, $\mathrm{HR}=1.88 ; 95 \% \mathrm{CI}: 0.80-4.43, P$ trend=0.18), but not for the mucinous subtype (of which there were only six cases in the highest quintile of intake). We observed a statistically significant positive trend of increasing risk of mucinous ovarian cancer across increasing quintiles of nitrite intake from processed meats $(P$ trend $=0.04)$; however, case numbers were small and the risk estimate in the highest quintile was not statistically significant (Q5 vs. Q1, $\mathrm{HR}=2.24$; 95\% CI: 0.76-6.61). Our results were unchanged when we excluded the $2.8 \%$ of the study population ( $n=4176$, including 20 ovarian cancer cases) who resided in census tracts with predicted nitrate levels greater than $10 \mathrm{mg} / \mathrm{l}$ for more than $50 \%$ of the census tract. We also stratified our analyses by age, education, smoking status, BMI, and physical activity; results were consistent with our main findings.

As vitamin C can inhibit $N$-nitrosation reactions, we evaluated the joint effect of nitrate or nitrite and vitamin $\mathrm{C}$ intake on epithelial ovarian cancer risk (Table 3). We considered women with low nitrite or nitrate intake and high vitamin $\mathrm{C}$ intake as the low risk referent group based on our hypothesis. The association between high nitrate/nitrite intake and either high or low vitamin $\mathrm{C}$ intake did not differ, and we did not observe any statistically significant interactions. We also evaluated the joint effect of nitrate or nitrite with vitamin $\mathrm{E}$ intake and did not observe any statistically significant interactions (data not shown).

\section{Discussion}

In this large prospective cohort of AARP members, we found that higher intake of dietary nitrate was associated with an increased risk of ovarian cancer by approximately $30 \%$ for women with the highest compared with those in the lowest quintile of intake. Although total nitrite intake was not associated with ovarian cancer risk, we identified a 34\% increase in risk and a statistically positive significant trend for animal sources of nitrite. Taken together, our results suggest that the source of the NOC precursors may be important for epithelial ovarian cancer risk.

One study previously evaluated the relationship between dietary nitrate intake and ovarian cancer and the findings were null and the case numbers more modest ( $n=102$; Weyer et al., 2001). Although no prior study has evaluated sources (i.e. plant vs. animal) of dietary nitrate and nitrite intake with respect to ovarian cancer risk, other studies have reported positive associations between high meat intake and ovarian cancer risk (Forman, 1987; La Vecchia et al., 1987; Mori and Miyake, 1988; Mori et al., 1988; Bosetti et al., 2001; Zhang et al., 2002). These findings are consistent with our observations for nitrite from animal sources. However, it should be noted that in a large cohort study including more than 325000 European women, there was no evidence of an association between consumption of animal foods (meat, fish, eggs, dairy products) and risk of ovarian cancer (Schulz et al., 2007).

Ingested nitrate is absorbed in the small intestine and $25 \%$ is excreted in the mouth, where oral bacteria reduce approximately $20 \%$ to nitrite (approximately $5 \%$ of ingested nitrate; Gangolli et al., 1994). There is great interindividual variability in endogenous production of 
NOCs, which is mediated by several known factors. Nitrite and reactive nitrogen species react with nitrosatable compounds, mainly amines and amides, to form NOCs (Mirvish, 1995, 1996; Bartsch and Frank, 1996; Grosse et al., 2006; Schulz et al., 2007). Processed meats are not only a source of nitrate and nitrite, but also a source of amines and amides, which are also precursors of NOCs. As a result, consumption of nitrate or nitrite from processed meats should theoretically result in more exposure to NOCs than plant-based foods; however, our results for nitrite appear to be due to animal sources, no association with processed meats was observed. As vegetables contain inhibitors of in-vivo $\mathrm{N}$ nitrosation such as vitamin C (Mirvish, 1996), we might expect a lack of an association between plant sources of nitrate and nitrite and ovarian cancer; this observation has been pointed to in several epidemiologic studies that have reported either no association or inverse associations between dietary nitrate intake and human cancers other than ovarian cancers. However, we did not observe an interaction between nitrate/nitrite and vitamin $\mathrm{C}$ intake and ovarian cancer risk.

The finding that animal sources of nitrite, but not processed meat sources, are positively associated with ovarian cancer risk was somewhat unexpected. Although the top contributor to daily nitrite intake in the NIH-AARP study population is coldcuts ( $7.2 \%$ of the daily nitrite variable), women consume lower levels of nitrite from processed meats than men ( $4.6 \%$ of nitrite intake in women is from coldcuts). In fact, the major animal source of nitrite in women is milk, as it contributes to $8.8 \%$ of nitrite intake in women. Our results suggest that additional animal sources of nitrite, such as milk, eggs, and ham (not luncheon meat), in addition to coldcuts and hotdogs, may increase the risk of ovarian cancer. Milk sugar lactose has been hypothesized as a risk factor for epithelial ovarian cancer previously because of possible direct toxic effects of its metabolites on oocytes or by compensatory gonadotropin stimulation (Fairfield et al., 2004). Investigators evaluated this hypothesis in the Nurses Health Study (Fairfield et al., 2004) and found that women who consumed one or more servings of skim or low-fat milk daily had a $32 \%$ higher risk of any ovarian cancer $(\mathrm{RR}=1.32 ; 95 \% \mathrm{CI}: 0.97-1.82)$ and a $69 \%$ higher risk of serous ovarian cancer $(\mathrm{RR}=1.69$; 95\% CI: 1.12-2.56) compared with women consuming three or fewer servings monthly. Further investigation of the role of nitrite from milk sources should be considered in future studies of ovarian cancer.

Drinking water nitrate can constitute the majority of nitrate intake when levels are near or above the MCL (Chilvers and Caygill, 1984). In a previous study, a positive association was observed across increasing quartiles of nitrate in the municipal water supply and ovarian cancer risk (Weyer et al., 2001); however, these findings were based on a limited number of cases. Although information on the primary source of drinking water was not obtained in this study, our findings were not altered when we excluded individuals living in areas where nitrate contamination of ground water is highly probable. Although a limitation of our study is that we did not have surface water estimates to identify persons for exclusion, more than half of the US population obtains drinking water from groundwater sources (Solley et al., 1993). Furthermore, surface waters in areas with contaminated groundwater are also likely to be affected. Lack of individual level drinking water information likely resulted in some misclassification of nitrate exposure from drinking water. Future investigation in this area, if possible, should utilize a study design that captures drinking water intake of nitrate in addition to dietary intake.

Our study had some additional limitations, including the possibility of measurement error associated with using a FFQ to assess usual diet, which, if nondifferential, could attenuate observed associations. The low response rate in this population is also a limitation as it could be a source of bias. In addition, measured nitrate values are not available for comparison for any region included in the study and the addition of measured values 
specific to the NIH-AARP population would improve the perceived validity of the exposure estimate. However, our study had numerous strengths, including the use of a detailed validated questionnaire to assess dietary intake of nitrate and nitrite and the wide range of intake: among participants in our study, the median intake of nitrate in the highest quintile was over five times that in the lowest quintile, and for nitrite, the highest quintile was over two times that in the lowest quintile. Other strengths include the prospective nature of the study, completeness of follow-up, the relatively large number of ovarian cancer cases, which allowed us to explore associations by histologic subtype, and the ability to adjust for a large number of potential confounding variables. As the follow-up time for this population increases, the power to evaluate this hypothesis will also be a strength relative to other smaller cohort populations.

In summary, we found a modest increased risk of epithelial ovarian cancer among women with high dietary nitrate intake and among those with a high intake of nitrite from animal sources. This study suggests that intake of NOC precursors may play a role in the etiology of ovarian cancer. These findings should be evaluated in additional studies with classification by histologic type, data on recent and long-term nitrate and nitrite intake, and detailed water consumption data.

\section{Acknowledgments}

The authors are indebted to the participants in the NIH-AARP Diet and Health Study for their outstanding cooperation. They also thank Sigurd Hermansen and Kerry Grace Morrissey from Westat for study outcomes ascertainment and management and Leslie Carroll at Information Management Services for data support and analysis.

This research was supported (in part) by the Department of Health and Human Service, Intramural Research Program of the National Cancer Institute, National Institutes of Health. Cancer incidence data from the Atlanta metropolitan area were collected by the Georgia Center for Cancer Statistics, Department of Epidemiology, Rollins School of Public Health, Emory University. Cancer incidence data from California were collected by the California Department of Health Services, Cancer Surveillance Section. Cancer incidence data from the Detroit metropolitan area were collected by the Michigan Cancer Surveillance Program, Community Health Administration, State of Michigan. The Florida cancer incidence data used in this study were collected by the Florida Cancer Data System under contract to the Department of Health (DOH). The views expressed herein are solely those of the authors and do not necessarily reflect those of the contractor or DOH. Cancer incidence data from Louisiana were collected by the Louisiana Tumor Registry, Louisiana State University Medical Center in New Orleans. Cancer incidence data from New Jersey were collected by the New Jersey State Cancer Registry, Cancer Epidemiology Services, New Jersey State Department of Health and Senior Services. Cancer incidence data from North Carolina were collected by the North Carolina Central Cancer Registry. Cancer incidence data from Pennsylvania were supplied by the Division of Health Statistics and Research, Pennsylvania Department of Health, Harrisburg, Pennsylvania. The Pennsylvania Department of Health specifically disclaims responsibility for any analyses, interpretations or conclusions. Cancer incidence data from Arizona were collected by the Arizona Cancer Registry, Division of Public Health Services, Arizona Department of Health Services. Cancer incidence data from Texas were collected by the Texas Cancer Registry, Cancer Epidemiology and Surveillance Branch, Texas Department of State Health Services. Cancer incidence data from Nevada were collected by the Nevada Central Cancer Registry, Center for Health Data and Research, Bureau of Health Planning and Statistics, State Health Division, State of Nevada Department of Health and Human Services.

\section{References}

Baker TR, Piver MS. Etiology, biology, and epidemiology of ovarian cancer. SeminSurg Oncol. 1994; 10:242-248.

Bartsch H, Frank N. Blocking the endogenous formation of N-nitroso compounds and related carcinogens. IARC Sci Publ. 1996; 139:189-201. [PubMed: 8923031]

Bogovski P, Bogovski S. Animal species in which N-nitroso compounds induce cancer. Int J Cancer. 1981; 27:471-474. [PubMed: 7275353]

Bosetti C, Negri E, Franceschi S, Pelucchi C, Talamini R, Montella M, et al. Diet and ovarian cancer risk: a case-control study in Italy. Int J Cancer. 2001; 93:911-915. [PubMed: 11519057] 
Byers T, Marshall J, Graham S, Mettlin C, Swanson M. A case-control study of dietary and nondietary factors in ovarian cancer. J Natl Cancer Inst. 1983; 71:681-686. [PubMed: 6578362]

Chilvers CIH, Caygill C, et al. A survey of dietary nitrate in well-water users. Int J Epidemiol. 1984; 13:324-331. [PubMed: 6490303]

Dunn JE. Cancer epidemiology in populations of the United States with emphasis on Hawaii and California and Japan. Cancer Res. 1975; 35:3240-3245. [PubMed: 1192400]

Fairfield KM, Hunter DJ, Colditz GA, Fuchs CS, Cramer DW, Speizer FE, et al. A prospective study of dietary lactose and ovarian cancer. Int J Cancer. 2004; 110:271-277. [PubMed: 15069693]

Forman D. Dietary exposure to N-nitroso compounds and the risk of human cancer. Cancer Surveys. 1987; 6:719-738. [PubMed: 3330686]

Friday, JE.; Bowman, SA. MyPyramid Equivalents Database for USDA Survey Food Codes, 19942002 Version 1.0. [Online]. USDA, ARS, Community Nutrition Research Group; 2006. Available from: http://www.ars.usda.gov/ba/bhnrc/fsrg/

Gangolli SD, Van den Brandt PA, Feron VJ, Janzowsky C, Koeman JH, Speijers GJ, et al. Nitrate, nitrite and N-nitroso compounds. Eur J Pharmacol. 1994; 292:1-38. [PubMed: 7867685]

Grosse Y, Baan R, Straif K, Secretan B, El Ghissassi F, Cogliano V. Carcinogenicity of nitrate, nitrite, and cyanobacterial peptide toxins. Lancet Oncol. 2006; 7:628-629. [PubMed: 16900606]

Hankinson, SE.; Danforth, KN. Ovarian cancer. In: Schottenfeld, D.; Fraumeni, JF., editors. Cancer epidemiology and prevention. 3. Oxford: Oxford University Press; 2006. p. 1013-1026.

Herrinton LJ, Stanford JL, Schwartz SM, et al. Ovarian cancer incidence among Asian migrants to the United States and their descendants. J Natl Cancer Inst. 1994; 86:1336-1339. [PubMed: 8064892]

Jemal A, Siegel R, Xu J, Ward E. Cancer Statistics, 2010. CA Cancer J Clin. 2010; 60:277-300. [PubMed: 20610543]

La Vecchia C, Decarli A, Negri E, Parazzini F, Gentile A, Cecchetti G, et al. Dietary factors and the risk of epithelial ovarian cancer. J Natl Cancer Inst. 1987; 79:663-669. [PubMed: 3116309]

Lück E. Chemical preservation of food. Zentralbl Bakteriol Mikrobiol Hyg B. 1985; 180:311-318. [PubMed: 3993260]

McKnight GM, Duncan CW, Leifert C, Golden MH. Dietary nitrate in man: friend or foe? Br J Nutr. 1999; 81:349-358. [PubMed: 10615207]

Mirvish SS. Inhibition by vitamins $\mathrm{C}$ and $\mathrm{E}$ of in vivo nitrosation and vitamin $\mathrm{C}$ occurrence in the stomach. Eur J Cancer Prev. 1996; 1 (Suppl 5):131-136. [PubMed: 8972308]

Mirvish SS. Role of N-nitroso compounds (NOC) and N-nitrosation in etiology of gastric, esophageal, nasopharyngeal, and bladder cancer and contribution to cancer of known exposures to NOC. Cancer Lett. 1995; 93:17-48. [PubMed: 7600541]

Moorman PG, Palmieri RT, Akushevich L, Berchuck A, Schildkraut JM. Ovarian cancer risk factors in African-American and white women. Am J Epidemiol. 2009; 170:98-606. [Epub 15 July 2009].

Mori M, Harabuchi I, Miyake H, Casagrande JT, Henderson BE, Ross RK. Reproductive, genetic, and dietary risk factors for ovarian cancer. Am J Epidemiol. 1988; 128:771-777. [PubMed: 3421242]

Mori M, Miyake H. Dietary and other risk factors of ovarian cancer among elderly women. Jpn J Cancer Res. 1988; 79:997-1004. [PubMed: 3142839]

Nolan BT, Hitt KJ. Vulnerability of shallow groundwater and drinking-water wells to nitrate in the United States. Environ Sci Technol. 2006; 40:7834-7840. [PubMed: 17256535]

Schatzkin A, Subar AF, Thompson FE, Harlan LC, Tangrea J, Hollenbeck AR, et al. Design and serendipity in establishing a large cohort with wide dietary intake distributions: the National Institutes of Health-American Association of Retired Persons diet and health study. Am J Epidemiology. 2001; 154:1119-1125.

Schulz M, Nöthlings U, Allen N, et al. No association of consumption of animal foods with risk of ovarian cancer. Cancer Epidemiol Biomarkers Prev. 2007; 16:852-855. [PubMed: 17416784]

Solley WB, Pierce RR, Perlman HA. Estimated use of water in the United States in 1990. US Geological Survey Circular. 1993; 1081:1993.

Subar AF, Midthune D, Kulldorff M, et al. Evaluation of alternative approaches to assign nutrient values to food groups in food frequency questionnaires. Am J Epidemiology. 2000; 152:279-286. 
Thompson FE, Kipnis V, Midthune D, et al. Performance of a food-frequency questionnaire in the US NIH-AARP (National Institutes of Health-American Association of Retired Persons) diet and health study. Public Health Nutrition. 2008; 11:183-195. [PubMed: 17610761]

Ward MH, Cerhan JR, Colt JS, Hartge P. Risk of non-Hodgkin lymphoma and nitrate and nitrite from drinking water and diet. Epidemiology. 2006; 17:375-382. [PubMed: 16699473]

Weyer PJ, Cerhan JR, Kross BC, Hallberg GR, Kantamneni J, Breuer G, et al. Municipal drinking water nitrate level and cancer risk in older women: the Iowa women's health study. Epidemiology. 2001; 12:327-338. [PubMed: 11338313]

Willett, WC. Nutritional epidemiology. New York: Oxford University Press; 1998.

World Health Organization. International Classification of Diseases for Oncology. Vol. 2001. Geneva: WHO; 2001.

Zhang M, Yang ZY, Binns CW, Lee AH. Diet and ovarian cancer risk: a case-control study in China. Br J Cancer. 2002; 86:712-717. [PubMed: 11875731] 


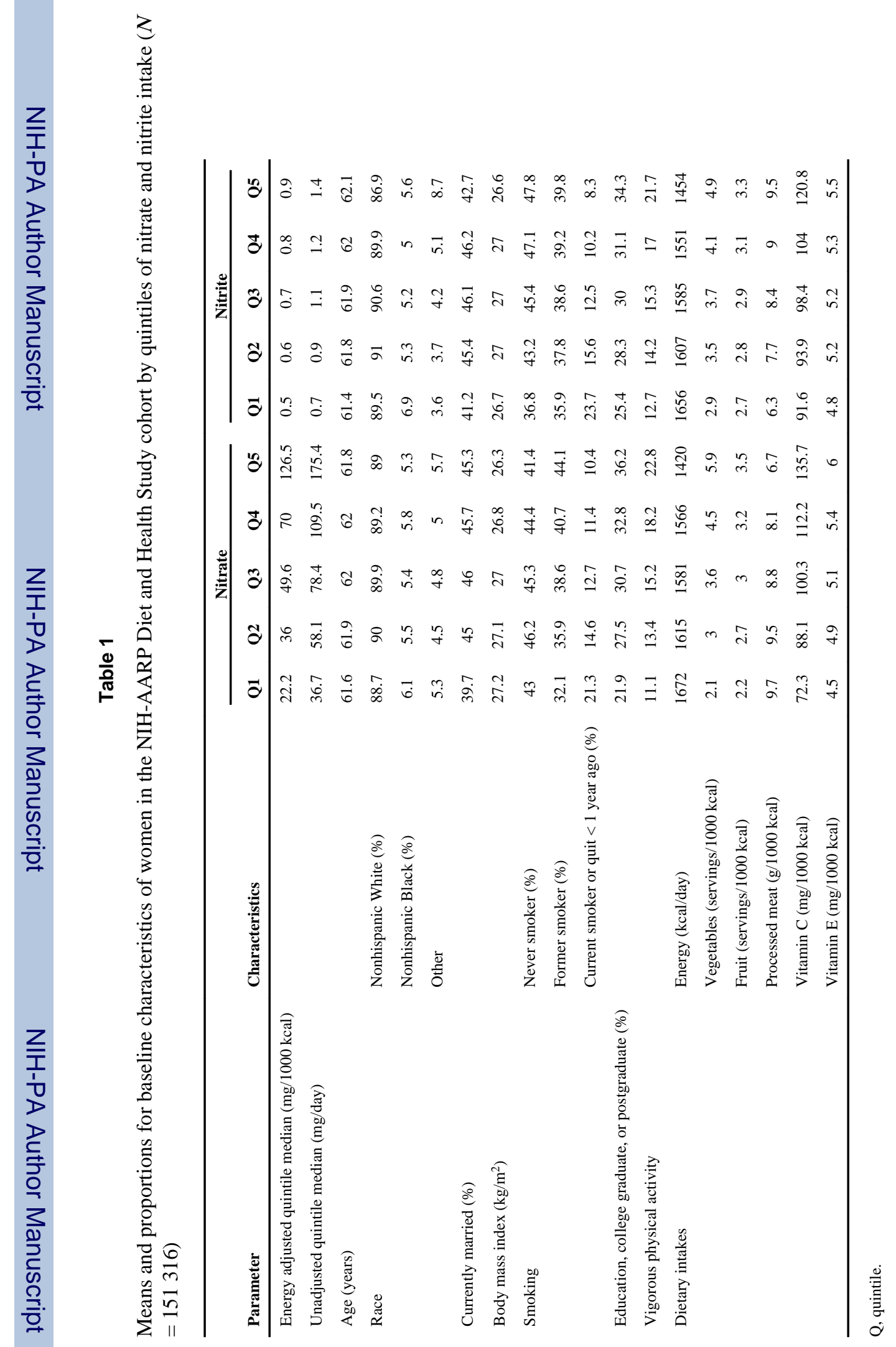




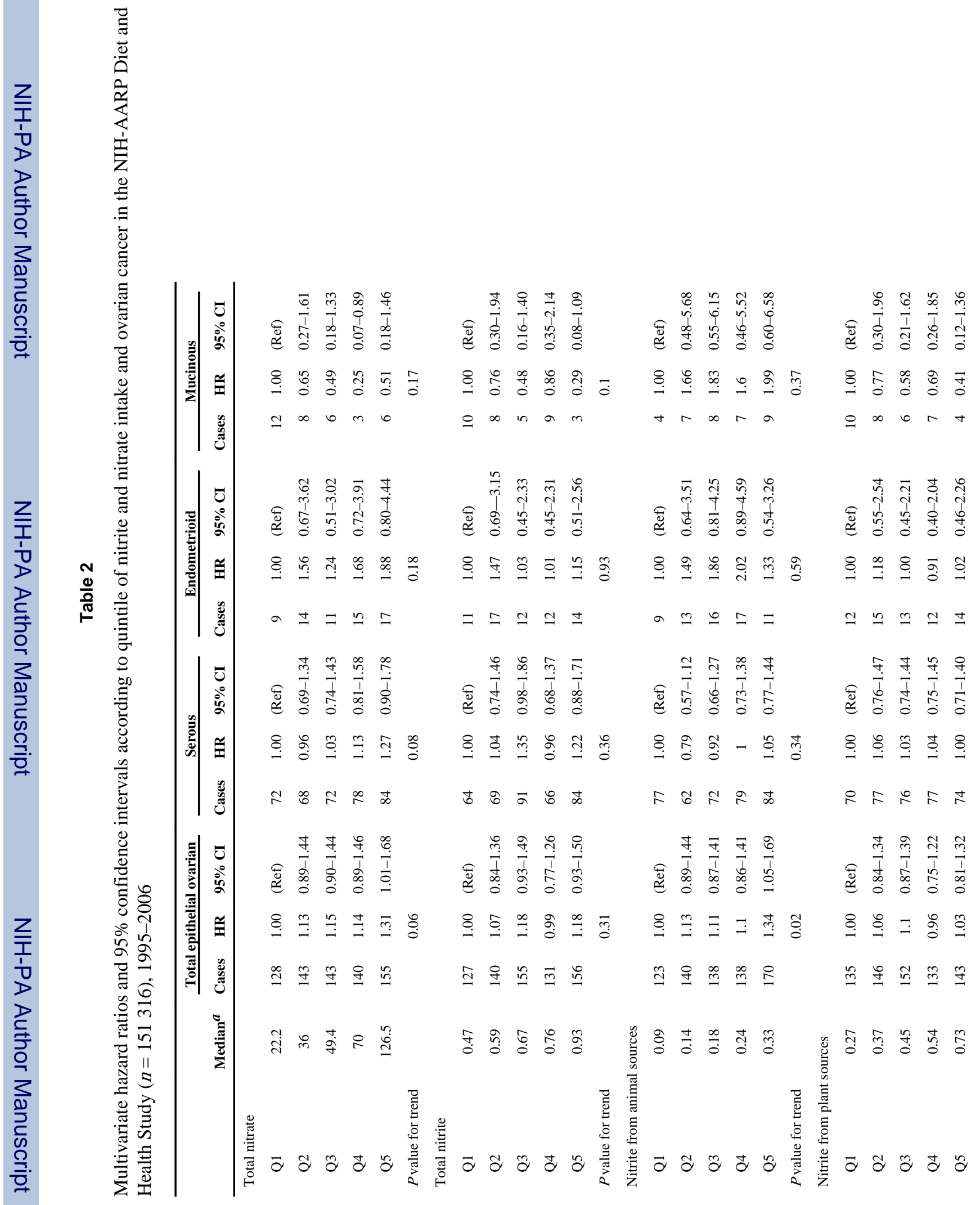




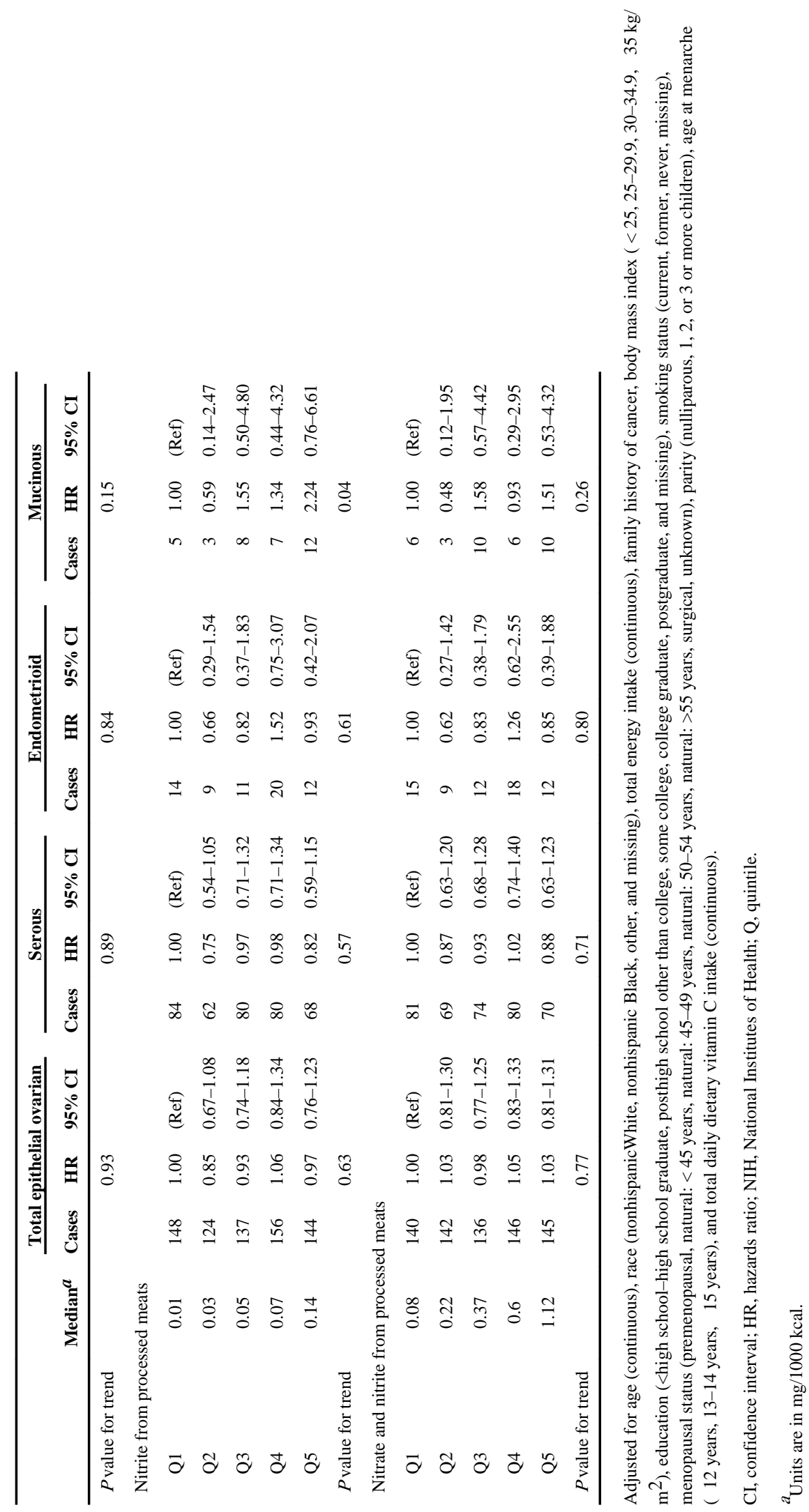


Aschebrook-Kilfoy et al.

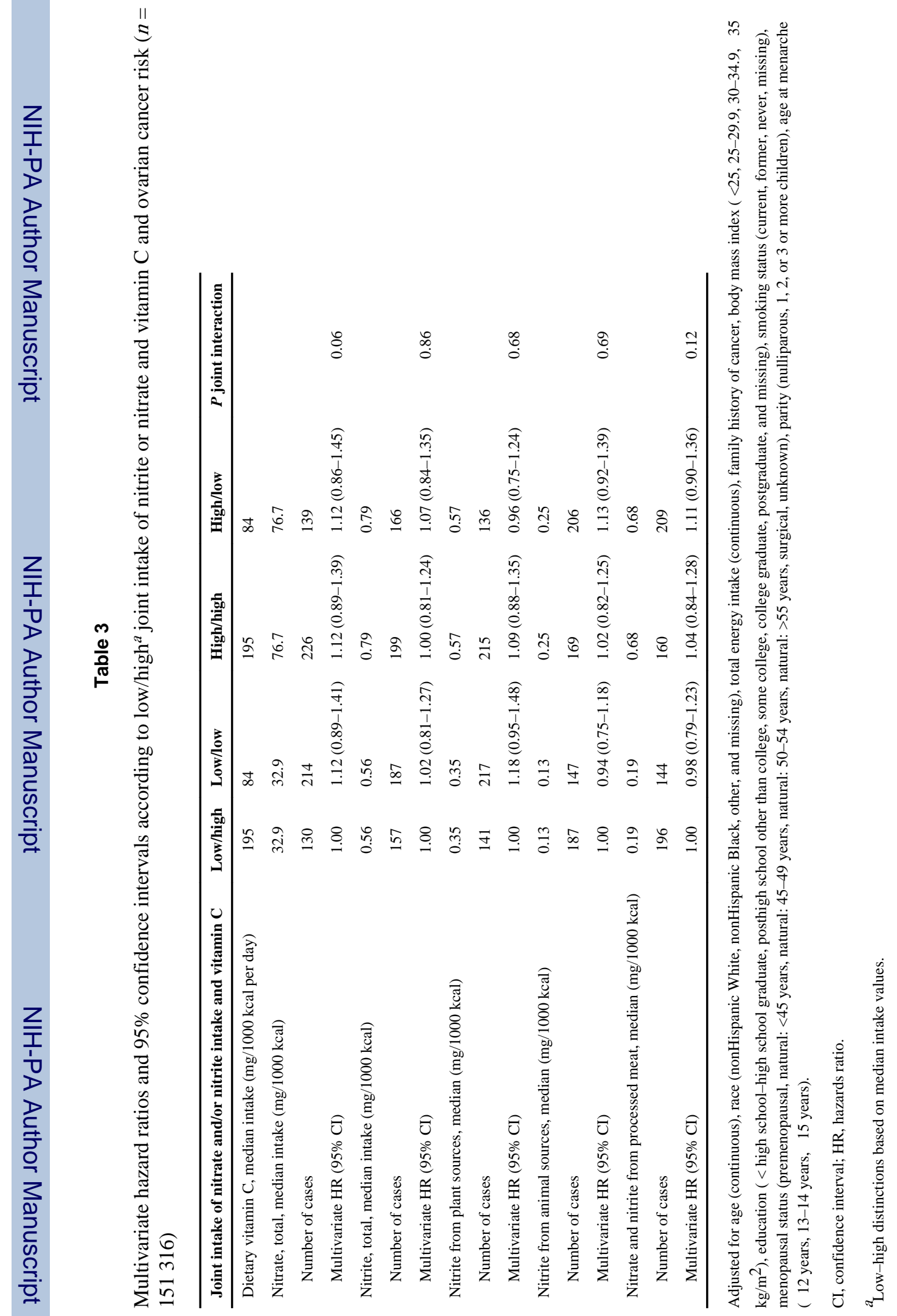

Eur J Cancer Prev. Author manuscript; available in PMC 2013 January 01. 